\title{
Expresiones mínimas de lo viviente en la obra robótica de Paula Gaetano-Adi
}

\author{
Nadia Martin \\ Consejo Nacional de Investigaciones Científicas \\ Universidad Nacional de Tres de Febrero \\ martin.nadia@gmail.com \\ Artículo bajo licencia Creative Commons \\ Atribución 4.0 Internacional (CC BY 4.0) \\ ENVIADO: 2019-03-02 \\ ACEPTADO: 2019-06-05
}

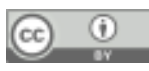

\section{RESUMEN}

Este trabajo aborda dos obras de Paula Gaetano-Adi con el objetivo de reflexionar -desde la teoría biopolíticaacerca de cómo tematizan el cuerpo viviente. Según se observa, la artista crea corporalidades robóticas que expresan experiencias mínimas del cuerpo físico y vivencial: la sudoración y la respiración. Propone, con ellas, una crítica al imaginario robótico del humanoide hiperinteligente vinculado a la idea de un cuerpo eficiente y productivo, como así también al binarismo cartesiano extendido a la dicotomía software/hardware. Se trata, entonces, de espacios de desborde del canon del arte robótico, que cuestionan sus modelos hegemónicos globalizados.

PALABRAS CLAVES

Arte robótico; arte tecnológico; Cuerpo; Biopolítica; Posthumanismo.

\section{RESUMO}

Este trabalho aborda duas obras de Paula Gaetano-Adi com o objetivo de fazer uma reflexão - a partir da teoria da biopolítica- sobre a maneira como se tematiza o corpo vivo. Se observa a criação de corporalidades robóticas que expressam experiências mínimas do corpo físico e vivo: o suor e a respiração. Com elas, propõe uma crítica ao imaginário robótico do humanoide superinteligente vinculado à ideia de um corpo eficiente e produtivo, assim como ao binarismo cartesiano estendido à dicotomia software/ hardware. Trata-se, portanto, de espaços de transbordamento do cânon da arte robótica, que questionam seus modelos hegemônicos globalizados.

\section{PALAVRAS-CHAVE}

Arte robótica, arte tecnológica, corpo, biopolítica, pós-humanismo.

\section{ABSTRACT}

This paper addresses two pieces of Paula Gaetano-Adi's work of art, with the objective of analyzing the way the living body is thematized in them. The artist creates robotic corporalities that express minimal experiences of the physical and experiential body: sweating and breathing. She proposes, thereby, a critique of the robotic imaginary of the hyperintelligent humanoid associated to the idea of an efficient and productive body, as well as a critique of the Cartesian binarism extended to the software / hardware dichotomy. They are, thus, spaces of overflow of the robotic art's canon, that question its globalized hegemonic models.

\section{KEYWORDS}

Robotic arts; Technological arts; Body; Biopolitics; Posthumanism. 


\section{INTRODUCCIÓN}

Referente temático, materia viva de expresión, dimensión analítica... El cuerpo, en el arte contemporáneo ha devenido en un campo de indagación central que moviliza inquietudes y fuertes posicionamientos tanto en la producción como en las perspectivas analíticas. Una de las razones que podrían explicar tal intensificación del interés contemporáneo en lo corporal, puede estar dado en que en tiempos de posthumanis$\mathrm{mo}^{1}$, la idea misma de organismo viviente ha sido puesta en una revisión crítica. Los desarrollos de las últimas décadas en campos como la biotecnología, la ingeniería genética, la robótica y inteligencia artificial han permitido, por primera vez en la historia, la generación y manipulación de la vida por medios artificiales. Es bajo sus impulsos que se extienden visiones post-orgánicas del cuerpo, en las que el mismo es entendido como código plausible de ser manipulado o materia extensible y mejorable mediante intervenciones quirúrgicas y prótesis tecnológicas. Se reproduce, así, un imaginario de superación de los dualismos modernos asociados al antropomorfismo humanista (Sloterdijk, 2000, 2001; Haraway, 1991). En este marco de referencia, se inscribe la propuesta productiva de un sector del arte tecnológico global en el que predomina una estética que podemos identificar marcada por la "obsesión tardoposmoderna por lo real" (Foster, 2001) y modulada en base a un imaginario tecnocientífico de corte "fáustico" (Sibilia, 2009)3. Tal es el caso de artistas emblemáticos como Eduardo Kac, Roy Ascott, Orlan o Sterlac, en cuyas obras la materia viviente (que muchas veces, es su propio cuerpo) es atravesada por intervenciones tecnológicas extremas.

En forma paralela a este circuito, existe otro sector de las artes tecnológicas que, si bien también toman para su propio dominio los debates de la manipulación tecnocientífica de lo viviente, lo hacen con otros procedimientos que se sirven de lo artefactural no tanto para la intervención sobre el plano de lo real (es decir, de las materias vivas) sino como referente temático y herramienta expresiva de nuevas figuraciones simbólicas. En este marco productivo, se identifica a la artista argentina Paula Gaetano-Adi. Así pues, este trabajo aborda dos de sus obras robóticas, con el fin de estudiar los modos en los que el cuerpo viviente es tematizado en ellas. El análisis se propone desentrañar algunas coordenadas ético-estéticas, desde las cuales se puede dar cuenta de modos locales, situados, de imaginación y significación de los cuerpos.

En nuestro acercamiento a estas producciones artístico-tecnológicas, las tensiones entre lo orgánico y lo maquínico anclan en un mayor debate filosófico-político: aquel que, recuperando las extensas investigaciones en biopolítica iniciadas por Michael Foucault, permite reflexionar sobre los límites porosos e inquietantes de lo humano con la monstruosidad (Foucault, 2000; Negri, 2007), como asimismo sobre las potencias inmanentes y del devenir en las que lo viviente se afirma (Deleuze y Guattari, 2008;

1 Significativos y diversos aportes críticos sobre posthumanismo pueden consultarse en Peter Sloterdijk (2000, 2011), Paula Sibilia (2009) y Rossi Braidotti (2015). Para profundizar en este debate de acuerdo a cómo se presenta el las artes tecnocientíficas contemporáneas, consultar: Kac (2008) y Kac y Antunes Rocca (2007).

2 De acuerdo al análisis de Hal Foster (2001), la modernidad estética buscó trascender la figura referencial (liberar los signos de sus referentes) y concentrarse en lo puramente formal; el arte moderno abogó por su no-objetividad, por su aproximación autónoma al signo y a la exploración de sus arbitrariedades (postura propia de la pintura abstracto-impresionista y los campos de color, además del paradigma teórico defendido por Clement Greenberg). Por su parte, la posmodernidad buscó regocijarse con la imagen en sí, en su pura libertad de forma y su contingencia enunciativa (marco en que se desarrolla tanto el arte pop como el minimalismo, y cuyo espíritu resume Danto en célebre Después del fin del arte). Debido a una ausencia de centro o sentido trascendental, el significado habría quedado "desatado", es decir, habría pasado a definirse como otro significante. De esta forma, se daría un proceso ilimitado de equivalencias intercambiables de los signos, que daría lugar a una estética de "imágenes simuladas y significantes esquizofrénicos". En este proceso de achatamiento de las profundidades metafóricas, los significantes tenderían a tornarse cada vez más puros, literales, llegando a una tardoposmodernidad que estaría obsesionada por corroborar la existencia de lo representado, recurriendo para ello a figuraciones abyectas. Como ejemplo de este tipo de estética, Foster recurre, entre otras obras, a Merde d'artiste: not exactly what it says on the tin de Piero Manzoni; a Descripción nostálgica de la inocencia de la infancia de Mike Kelley; a Dick/Jane de John Miller; al Fruto Cocido de Zoe Leonard; e incluso cierta producción fotográfica de Cindy Sherman.

3 Paula Sibilia (2009) resume dos grandes paradigmas actitudinales ante la tecnociencia: el primero, basado en el mito de Prometeo, se serviría de la técnica con un fin de conocimiento de "la verdad del mundo" orientada al "bien común", pero asumiría un límite ante el origen de la vida y la evolución biológica; el segundo, referiría a una corriente fáustica guiada por una voluntad de superación y control infinitos, por una vocación ontológica de lucha contra las limitaciones del cuerpo y por el deseo de crear vida y modificarla. Resulta posible comprender estas dos tradiciones en relación con Heidegger: la primera estaría vinculada al desocultar-poético y la segunda al explotar-provocante. 
Derrida, 2008). Se entiende, así, que estas producciones artístico-tecnológicas resultan un terreno estratégico para estudiar las marcas de fantasías -monstruosas y/o maravillosas- acerca del cuerpo que asedian la contemporaneidad. Pero también los modos en los que la sociedad tramita imaginariamente las dificultades de articulación de la estructura comunitaria.

\section{CUERPO QUE SUDA}

Paula Gaetano Adi (San Juan, 1981) es una artista, docente e investigadora en arte electrónico argentina. ${ }^{4}$ Su primer agente robótico autónomo, creado en $\mathbf{2 0 0 5}$, consiste en una semiesfera blanda de sesenta centímetros de diámetro y treinta de alto, cuya superficie de látex color beige (que simula la piel de un humano blanco) le aporta una apariencia orgánica pero no-antropomórfica. Sin ojos, sin orejas ni extremidades, inhabilitada también para el movimiento, su única capacidad de expresión radica en la sudoración. Su "piel artificial" funciona como interfaz que organiza al tacto como única forma de percepción: cuando el público la presiona, se activa un dispositivo electrónico que bombea agua a través de finas mangueras de plástico dispuestas en el área subcutánea. Así, tal y como refiere su mismo título, Alextimia ${ }^{5}$ consiste en un robot cuya cualidad es su incapacidad de verbalizar las emociones: en cambio, al contacto, transpira.

Desde los desarrollos históricos y téoricos de Foucault, los supuestos naturalistas y ontologizantes de la vida biológica de los cuerpos han sido desplazados, para advertir que "la vida" es siempre ya artificial, en tanto sólo se nos presenta de acuerdo a los modos en que está modelada, intervenida por las tecnologías del poder. Esta división, operada incluso en el seno mismo del ser humano, será caracterizada por Agamben (2006a: 75-76) como “máquina antropológica”. Según el autor analiza, entre lo humano y lo no humano, entre el hablante y el mero viviente,

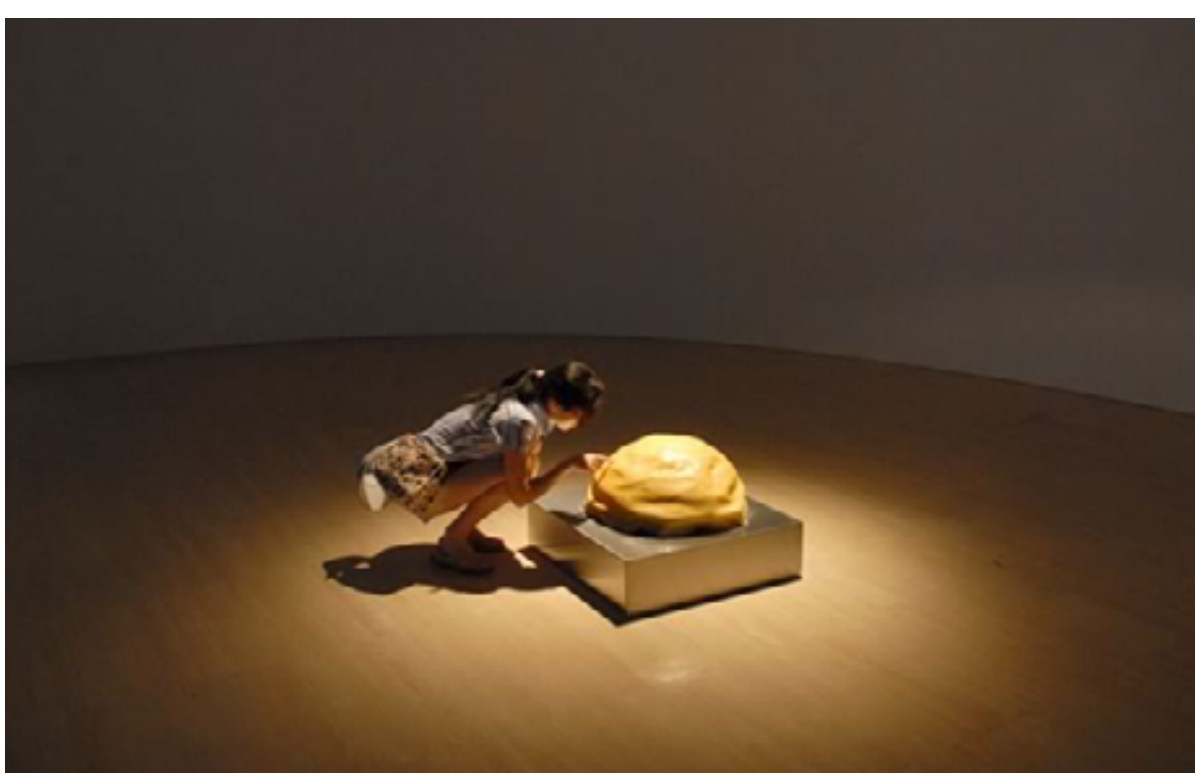
existiría un espacio abierto, una zona vacía, y en el centro mismo de esta indiferencia se instituiría (desde ya, histórica y políticamente) una separación mediante la que lo humano sería producido en oposición a cierta "vida desnuda" a la que estarían destinados los ya no, aún no o todavía no-humanos. Siguiendo los desarrollos de Roberto Espósito (2006) la problemática puede ser comprendida a la luz de los conceptos de Zoé y Bios. Mientras la primera sería aquella vida biológica percibida como ahistórica e indiferenciada, ontológicamente asociada a lo animal en los cuerpos, la segunda consistiría en aquella vida individualizada, identificada con una subjetividad y calificada en los términos del derecho, la vida política y el acceso a la palabra, al logos, a la narración de sí.

Imagen 1. Alexitimia, 2005 (Imagen: cortesía de la artista)
Alexitima pareciera inquietar estas divisiones, volverlas porosas, tensar los mecanismos (bio)políticos que permiten reconocer un cuerpo como humano. Esto es evidente desde su morfología, que si bien remite a la organicidad humana no respeta las proporciones antropomórficas. Pero una clave más sutil

$4 \quad$ Formada en Comunicación Audiovisual por la Universidad Blas Pascal y Master en Fine Arts por el programa de Arte \& Tecnología de la Ohio State University, actualmente inscribe su actividad en la Rhode Island School of Design (RISD), Estados Unidos. Un eje que atraviesa sus trabajos, es la exploración de los efectos y afectos que los discursos tecnocientíficos generan en los espacios de encuentro entre lo humano y lo maquínico. reconocimiento: ganadora en la categoría Proyecto Multidisciplinario Experimental LIMB $\varnothing$ de la $4^{\circ}$ edición del Premio MAMBA -Fundación Telefónica (2005), obtuvo también en 2006 el Primer premio en el reconocido concurso internacional VIDA 9.o, de Fundación Telefónica de España. 
de esta lectura radica en la propuesta conceptual que organiza la artista, anclada en la figuración de un cuerpo cuya mayor cualidad más característica es su incapacidad de verbalizar las intensidades y las potencias del propio cuerpo. Como ha sido remitido, una de las características con las que el humano ha delimitado su propio dominio, diferenciándose de otros animales y seres vivientes, es el lenguaje, la posesión del logos. Tal y como ha sido reconstruido por Derrida (2008) en la tradición filosófico-política occidental, el logos ha sido el elemento fundamental de un acto reflexivo (para la conciencia de un "yo", o aún más, para un "nosotros" en el que el humano se reconoce cada vez) y para la posibilidad de una historia común, para la narración de una autobiografía humana. Y es esta misma tradición la que ha establecido su propio logos, su orden de significación como confín. Todo lo que históricamente ha caído fuera de él, ha sido percibido como salvaje, bárbaro o insumiso, relegado al terreno de lo sin-sentido, de lo inarticulable o, aún, de lo insignificante y por ello mismo prescindible, separable e incluso exterminable.

Tales son las ansiedades y preocupaciones que la obra dispara. Alexitimia evoca a un cuerpo humano pero lo sitúa en el límite de lo reconocible; y si bien insta al tacto y al encuentro, clava en el instante mismo de esta aproximación una pregunta por los límites que definen a lo propiamente humano, como asimismo por los términos en los que dicho reconocimiento se efectúa.

\section{CUERPO QUE RESPIRA}

En esta misma línea de indagación, y también anclada en la pregunta por el comportamiento puramente corporal de los robots en su interacción con los espectadores, continúa Ánima, la siguiente obra robótica que Paula Gaetano-Adi produce en 2009. De características objetuales similares a la anteriormente descripta, esta semiesfera de látex detenta un orificio en su superficie que, cuando el público se acerca, se hincha y deshincha en un proceso de dilatación y cierre alternado. De esta forma, se trata de un robot cuyo único comportamiento, reactivo a la cercanía del espectador, es la respiración.

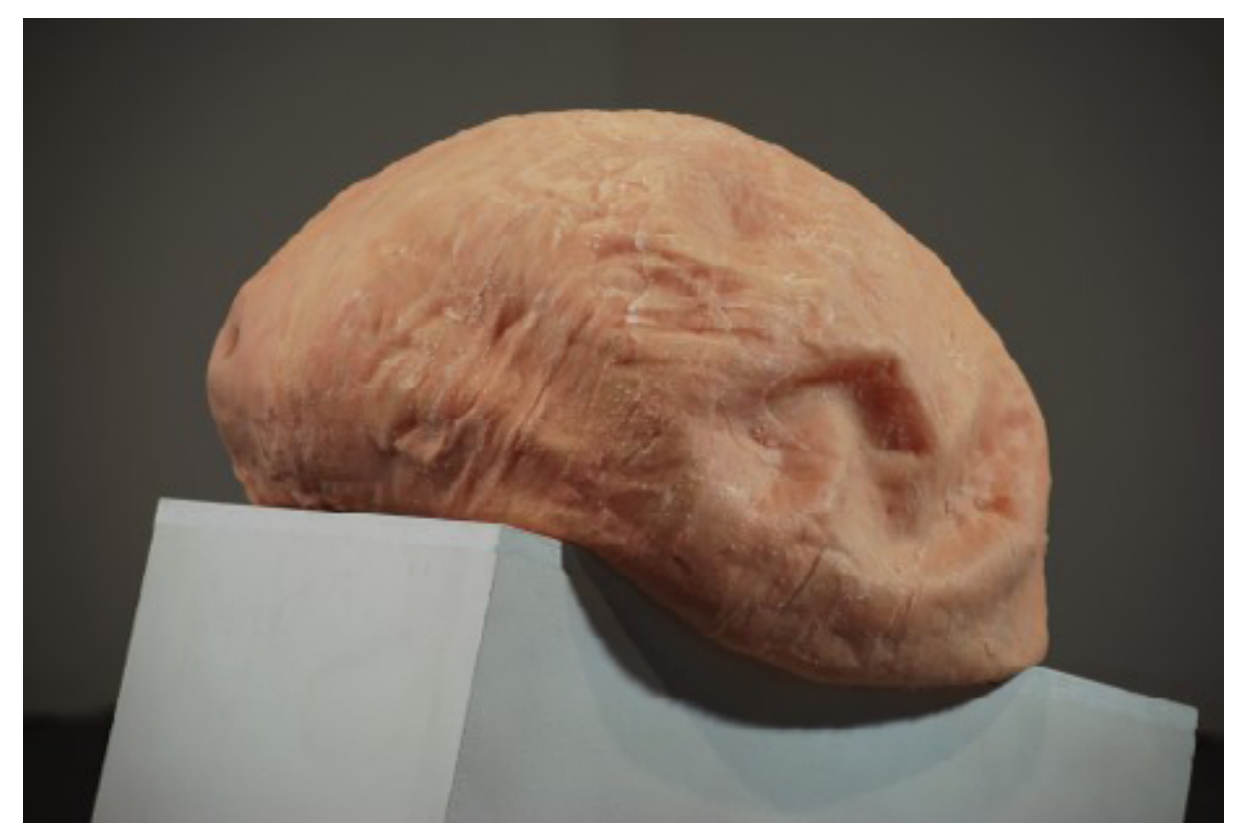

Imagen 2. Ánima, 2009 (Imagen: cortesía de la artista)

El título de la obra se vincula etimológicamente al alma. Nuevamente, aquí, uno de los "propios" de lo humano en tanto animal con alma. Sin embargo, el término también refiere en su raíz latina al aire, al aliento, al soplo; sentido en el que focaliza esta obra. En este caso, la respiración, lejos de ser algo propio de lo humano, señala un fondo de indiferenciación en el que todos los seres vivos encuentran un suelo en común. Ánima expresa el sobrecogimiento de un cuerpo disminuido a una mínima expresión de lo viviente, a una vida ni siquiera biológica, y en tanto artificialidad: inútil, sin función, improductiva. En este sentido ciertos desplazamientos, ciertas dislocaciones se operan en entre lo orgánico y lo maquínico. Nos encontramos aquí ante la excepción: una tecnología que respira.

Aún así, esta criatura robótica lejos de respirar apaciblemente se agita cuando el espectador se aproxima. El contacto, el intercambio, las alianzas parecieran impedidas: todo lo que expresa este cuerpo, nuevamente, es temor. Todo ser-en-común, toda intención de comunidad pareciera previamente impedida. En este punto, la obra estimula algunas reflexiones, en las que insiste la teoría política postfundacional contemporánea, acerca de las posibilidades de estructuración comunitaria en nuestro tiempo histórico. Desde que las experiencias más terribles del siglo XX dejaron al descubierto que en nombre de la comunidad y de la humanidad, se habían movilizado las más intensas capacidades de autodestrucción, resultó imposible pensar el ser-juntos según cualquier modelo del "ser” en general (es decir, en función de las esencias comunitarias). Como observara Jean-Luc Nancy en el prólogo a Communitas. Origen y 
destino de la comunidad[2012 (1998)] de Roberto Espósito, en la actualidad se ha vuelto inviable seguir basando el sentido de la comunidad en cualquier forma de "lo dado" (la sangre, la esencia, la filiación, el origen, la naturaleza, la identidad orgánica o mística, etc.). Así pues, a través de diversas figuras -"resto indivisible" (Zizek, 2013), "antagonismo radical" (Laclau y Mouffe, 1987), "cómputo erróneo" o "desacuerdo" (Ranciere, 1996)- autores contemporáneos han dado cuenta de que, lejos del pacto político entre individuos iguales, en el origen de todo orden social yace su misma imposibilidad intestina.

Ánima pareciera recuperar las ansiedades de un orden social siempre contingente, que no logra cuajar, suturarse, articular un tejido sólido para la vida con otros. Aún así, se ofrece como cuerpo híbrido, enrarecido, entre lo orgánico y lo maquínico, entre lo meramente viviente y lo propiamente humano; y así, proponiendo un ejercicio de (re)reconocimiento, plantea también la posibilidad siempre abierta, siempre latente, de definir nuevos órdenes -desde ya, comunes- de lo sensible.

\section{HUMANOIDES MONSTRUOSOS}

Las obras que hemos visto poseen, desde su interfaz, una apariencia orgánica y epidérmica. Por su parte, sus comportamientos (mecanismos de sudoración y respiración) evocan al cuerpo viviente. Sin embargo, estos cuerpos parecieran reducidos a una mínima función, al punto de que no parecieran aptos para desempeños tan vitales como la alimentación y el apareamiento. A esto se suma la resistencia de estos organismos robóticos a los parámetros de mímesis y proporción humanos y/o animales: en su apariencia amorfa, inclasificable, se objetivan (se vuelven presentes) seres inexistentes (un mero órgano sintético con un lenguaje puramente somático). Y estas condiciones, vuelven a estas obras verdaderas criaturas monstruosas.

Foucault distingue la filiación que hay entre anormalidad y monstruosidad. El monstruo sería una combinación entre lo imposible y lo prohibido, una excepción a la vez que una violación de la normalidad; y en este sentido, es "una noción jurídica -jurídica en el sentido amplio del término, claro está, porque lo que define al monstruo es el hecho de que, en su existencia misma y su forma, no sólo es una violación de las leyes de la sociedad, sino también de las leyes de la naturaleza-" (Foucault, 2000: 61). Pero a la vez, la normalidad es un concepto (bio) político, en tanto conlleva cierto ejercicio de poder (sobre los cuerpos). Toda norma implica un principio clasificatorio (de la materia viva) y una intención de corrección de las desviaciones (de las anormalidades). "Su función no es excluir, rechazar. Al contrario, siempre está ligada a una técnica positiva de intervención y transformación, a una especie de proyecto normativo" (Foucault, 2000: 57).

En este sentido, estas máquinas que sudan o respiran, recuperan de la escultura problemas de la forma y de la materialidad, mediante una propuesta conceptual que se organiza en tanto monstruosa, por una doble desviación. Desviación, por un lado, de los parámetros de normalidad establecidos por los referentes corporales vivos; por el otro, de los modelos hegemónicos en robótica. Máquinas inútiles, improductivas, con algunas cualidades orgánicas y mecanismos electrónicos simples, desafían el paradigma tecnocientífico de la eficiencia y la racionalidad: el robot humanoide hiperinteligente. Como indica la artista en una entrevista personal concedida en octubre de 2018:

“Creo que lo tecnológico en sí mismo tiene que ver con la propuesta conceptual de mis obras. A mí me interesa lo tecnológico como discurso, como problemática a tematizar. En ese sentido es una herramienta que lo que permite es no hacer una representación de algo. Es decir, no elijo pintar un cuadro para hablar acerca de los problemas de las tecnologías. Para mí, lo material habla por sí mismo: los movimientos mecánicos, eso en sí mismo ya es discurso."

En esta dirección, sirviéndose del soporte material de su misma obra, la artista discute con el binarismo cartesiano extendido contemporáneamente a la dicotomía software/hardware. En oposición crítica al predominio de los proyectos de Inteligencia Artificial, la artista propone una experiencia artificial del cuerpo físico y vivencial; una corporalidad robótica pura, totalmente somática, que no puede tramitar intercambios complejos con el entorno, sino que presenta un comportamiento simple, reducido a la sudoración ante el contacto o a la respiración ante el acercamiento.

“Mis robots son muy humildes. No tienen intenciones de 
sofisticación. Por el contrario, tienen la intención de bajar los imaginarios en robótica a la humanidad, a humanizarlos. Para mí, la robótica es un discurso que surge como esclavo del humano y para suplantarlo, para duplicarlo... pero dentro de lo que se considera humano, se suelen dejar afuera un montón de cosas. En este sentido creo que mi obra plantea preguntas que, desde ya no resuelve, pero tienen que ver con pensar de qué humano hablamos cuando hablamos de humano".

Así, de cara a la proliferación de los dispositivos interactivos y los funcionamientos enmarcados en el paradigma "topdown" (Penny, 1995) en la escena electrónica internacional, Gaetano-Adi organiza máquinas reactivas (actúan mediante un comando on/off) que, por la combinación de sus cualidades materiales, formales y conceptuales, plantean un ejercicio perceptivo ubicado en los extremos fenomenológicos de lo humano y lo artificial; de lo viviente y lo inorgánico; dispositivos de contacto entre mundos, que invitan a posar la mirada en los límites de lo identificable.

\section{REFLEXIONES FINALES: LA INMANENCIA DE LA VIDA}

A lo largo de este trabajo hemos abordado dos obras robóticas de la artista argentina Paula Gaetano-Adi, con el fin de analizar los modos en los que lo corporal es tematizado. En ellas, hemos observado cómo se modulan algunos interrogantes (y se tramitan imaginariamente algunas ansiedades) propios de nuestro tiempo histórico, en el que los avances en tecnociencia han logrado la generación y manipulación artificial de la vida.. En primera instancia, su obra genera reflexiones acerca de qué es lo propio, lo exclusivo o lo definitorio de la condición humana. Inquietud que redunda en una indagación acerca de los procesos sujetivatorios que se ponen en juego en todo orden (bio)político. Sus figuras imprecisas, híbridas, monstruosas, desajustan algunos parámetros del reconocimiento; y así, movilizan también ciertos fundamentos de los intercambios intersubjetivos. En este sentido, también la obra pone de manifiesto algunas dificultades que las sociedades contemporáneas encuentran para articular su ser-en-común, el sentido de la comunidad (en tanto que el principio de igualdad o semejanza fundamentada en el "ser" pareciera flaquelar). Pero además, estas producciones abordan críticamente algunas tensiones que se generan en el seno del desarrollo histórico de la tecnociencia. El mismo ha extendido en la contemporaneidad un modelo corporal dispuesto a ser manipulado e intervenido por herramientas que, por medios artificiales, permiten perfeccionarlo según un modelo de eficiencia y productividad. Desde el corazón mismo del cruce entre arte y la tecnociencia en el contexto contemporáneo, estas piezas configuran espacios de desborde del canon del arte robótico, cuestionando sus modelos hegemónicos globalizados. Y sin abandonar los espacios de interpenetración entre lo orgánico y lo artificial, entre el humano y el robot, la artista propone algunas reflexiones acerca de los límites y las potencias del cuerpo, recuperando desde el terreno del artefacto, algunas mínimas expresiones de lo viviente. Algo de estas figuras corporales enrarecidas, aparentemente reducidas o limitadas, sugieren cierta vida impersonal, y sin embargo singular, que puja en ellas. La pura intensidad de un cuerpo en el devenir de su aumento o disminución de poder, de su potencia, de su potencial, de sus virtualidades. En estas obras pareciera percibirse lo que Deleuze llamaría el "puro plano de inmanencia", algo que "se presenta como un puro flujo de conciencia a-subjetiva, conciencia prereflexiva impersonal, duración cualitativa de la conciencia sin yo" (2007: 35). En un tiempo en el que el poder pareciera capturar como nunca antes la materia viviente del cuerpo para normalizarla, domesticarla y volverla eficiente a los fines (re)productivos, estas obras parecieran sugerir la resistencia de una potencia inmanente: la latencia de cierto principio de autoafirmación de la vida en sí misma. 
Agamben, G. (2006a). Lo abierto. Buenos Aires: Adriana Hidalgo.

Agamben, G. (2006b). Homo sacer. Poder soberano y vida desnuda. Valencia: PreTextos.

Braidotti, R. (2015). Lo posthumano. Barcelona: Gedisa.

Calabrese, O. (1987). La era neobarroca. Madrid: Cátedra.

Deleuze, G. (2007). “La inmanencia: una vida...” en: Ensayos sobre biopolítica. Excesos de vida. Giorgi, G. y Rodríguez, F (Comps). Buenos Aires: Paídós.

Deleuze, G. y Guattari, F. (2008). “Devenir-intenso, devenir-animal, devenir-imperceptible" en: Mil Mesetas. Capitalismo y Esquizofrenia. Valencia: Pre-Textos.

Derrida, J. (2008). El animal que luego estoy si(gui)endo. Madrid: Trotta.

Dubois, P. “Maquinas de imagen: una cuestión de línea general”. (2001) En: Video, Cine Godard, Buenos Aires: Libros del Rojas (UBA), 2001. Foster, H. El retorno de lo real. La vanguardia a finales de siglo. Madrid: Akal.

Espósito, R. (2006). Bios. Biopolítica y filosofía. Buenos Aires: Amorrortu.

Espósito, R. (2012 [1998]). Communitas. Origen y destino de la comunidad. Buenos Aires: Amorrortu.

Foster, H. (2001). El retorno de lo real. La vanguardia a finales de siglo. Madrid: Akal.

Foucault, M. (2000). Los Anormales. Buenos Aires: Fondo de Cultura Económica.

Foucault, M. (2002). Vigilar y castigar. Nacimiento de la prisión. Buenos Aires: Siglo XXI.

Haraway, D. (1991). Simians, cyborgs, and women: the reinvention of nature. New York: Routledge.

Jasso, K. (2008). Arte, tecnología y feminismo: nuevas figuraciones simbólicas. México: Universidad Iberoamericana.

Laclau, E. y Mouffe, C. (1987). "Más allá de la pisitividad de lo social: antagonismo y hegemonía”. En: Hegemonía y estrategia socialista. México: Siglo XXI.

Nancy, JL. (2012 [1998]). “Conloquium”, en: ESPÓSITO, Roberto. Communitas. Origen y destino de la comunidad. Buenos Aires: Amorrortu.

Negri, A. (2007). "El monstruo político. Vida desnuda y potencia”. En Ensayos sobre biopolítica. Exceso de vida. Gabriel Giorgi y Fermín Rodríguez (comps.). Buenos Aires: Paidós. 93-139.

Ranciere, J. (1996). El desacuerdo. Política y filosofía. Buenos Aires: Nueva Visión.

Sibilia, P. (2010). El hombre postorgánico: Cuerpo, subjetividad y tecnologías digitales. México: Fondo de cultura económica.

Sloterdijk, P. (2000). Normas para el parque humano. Madrid: Siruela.

Sloterdij, P. (2001). "El hombre operable. Notas sobre el estado ético de la tecnología génica”. En: Artefacto/4.

Zizek, S. (2013). El resto indivisible. Buenos Aires: Godot. 